Univerziteta u Sarajevu

Filozofski fakultet

isanovicahmed2@gmail.com

\title{
SATIRIČNO RAZOBLIČAVANJE PRIVIDNOG MORALA \\ I POLITIČKOG DJELOVANJA U DRAMSKOM \\ STVARALAŠTVU IVANA CANKARA
}

\begin{abstract}
Analizirajući satirične postupke u dramama $Z a$ dobro naroda, Sluge, Kralj Betajnove i Sablazan u Šentflorijanskoj dolini, nastojim istaknuti angažirani karakter Cankarevog dramskog stvaralaštva koji svoju primarnu tehniku pronalazi u satiri kao savršenom etičkom i subverzivnom postupku kojim Cankar napada i razobličava negativne strane aktualne mu zbilje, pokazujući time i težnju ka promjeni sociopolitičkog konteksta.
\end{abstract}

Ključne riječi: satira, drama, angažirana književnost, sociopolitički mora

Celo tvoje delo [...] svelo se na pokazivanje svetu žalosne slike sadašnjih dana Ivan Cankar

Cilj glume, odvajkada i sada, bio je i jeste da bude, tako reći, ogledalo prirode; da pokaže vrlini njeno rođeno lice, poroku njegovu rođenu sliku, a samom vremenu i biću sveta njegov oblik i otisak (Cankar 1946: 101), riječi su koje izgovara Šekspirov Hamlet, koje Cankar uzima kao moto drami Sluge, a u kojima se može, kako Ziherl (1956) navodi, prepoznati i estetski princip svih Cankarevih realističkih drama. Načelo Cankarevog stvaralaštva, čija se motivirajuća snaga ogleda u razumijevanju umjetnosti kao mjesta angažiranosti, temelji se na kritičkom i prezirućem odnosu prema savremenoj mu zbilji, ukazujući na socio-političke i moralne anomalije s kojima se susreće slovenačko društvo na prelazu iz 19. u 20. stoljeće. Želeći djelovati na socio-političko stanje, Cankar svojim stvaralaštvom nastoji, prvenstveno, identificirati negativne pojave aktualne stvarnosti, a potom, kritičkim odnosnom i podrivajućim elementima uticati na promjenu deformisanih socio-političkih prilika i moralnog sunovrata. Cankareve drame kao oblik 
angažirane književnosti ${ }^{57}$, primjer su usklađivanja književnog djela sa političkim i društvenim idejama koje je zastupao ${ }^{58}$, a koje svoju primarnu tehniku pronalaze u satiri.

Ne samo kao umjetnički, već i kao diskurzivni postupak, satira je sveprisutna pojava, posebno zastupljena u prelomnim povijesnim periodima, a opće je mjesto, kako Lukić (2018) navodi, da nema društva bez nekog oblika satire. Prema Lešićevoj natuknici u Rečniku književnih termina satira označava književno djelo u kojem je na podrugljiv $i$ duhovit (i kritičan, ali ne nužno komičan) način izražena oštra osuda jednog društva ili ljudskih mana. Njen osnovni cilj je da ukaže na društvene ili moralne slabosti, poroke i zloće, da ih izvrgne ruglu i podsmijehu i da na taj način doprinese njihovom otklanjanju (Lešić 1986: 694). Pošto je satiri imanentno suprotstavljanje i kritički napad, njome se uvijek nastoji iskomunicirati određeni svjetonazor, ideal, prepoznatljiv etički, socijalni i politički stav, što je ujedno i jasan iskaz piščevog pogleda na svijet. U zauzimanju kritičkog stava prema društvenim okolnostima pisca motivira osjećaj moralnog poziva i brige za javni i društveni interes. Za Nortropa Fraja (2000) satira je oblik ratoborne ironije, koja se temelji na snažno izraženom moralnom stavu autora koji pretpostavlja norme na osnovu kojih se predmet napada prikazuje kao apsurdan ili groteskan. Prema Fraju, dva su svojstva najvažnija za satiru: prvi je duhovitost i humor, a drugi je predmet napada. ${ }^{59}$ Prema tome, napad bez humora, što je česta pojava, je granični oblik satire, što i jeste i nije satira. Svijet satire je svijet koji je iskočio iz zgloba. To je svijet prepun pokvarenosti, niskosti, požude, potkupljivosti, gluposti, zlobe, pohlepe, ukratko - ljudske duhovne mizerije uopće (Lešić 1986:

${ }^{57}$ Ideju o angažiranoj književnosti najsnažnije je promovirao Sartr (1981), za koga je književnost jedna društvena funkcija, njen zadatak jeste angažovanost, ali, bitno je istaknuti kako imperativom angažiranosti Sartr ne želi potisnuti literaturu, misleći pod tim ono estetsko, imanentno književno što bi ruski formalisti nazvali literarnošću. Ono što Sartr prezire jeste besciljnost Umetnosti radi umetnosti, koja potpuno zanemaruje izvan-umjetnički kontekst. Zadatak književnosti je u angažiranosti, naša je namera da doprinesemo izvesnim promenama u Društvu koje nas okružuje [...] zato se pridružujemo onima koji hoće $u$ isto vreme da izmene čovekov društveni položaj i njegovu koncepciju o sebi (Sartr 1981: 7).

${ }^{58}$ Više vidi Cankar, Ivan. Eseji kritike i feljtoni. Pr. Milica Carcaračević. Beograd: Prosveta, 1956.

${ }^{59} \mathrm{Za}$ Jolesa (2000) je, također, satira napad, ali prema onome s čim nemamo i ne želimo imati ništa zajedničko, dok je ironija napad prema nečemu što je naše ili nam blisko. 
695, 696). Iz činjenice da je satira glavni kritički instrument Cankarevog dramskog stvaralaštva, formirana je i osnovna pretpostavka rada koja glasi da je satirički čin par exellance moralni čin, čin negodovanja, ali i subverzivni čin. Podrazumijevajući prepoznatljiv satiričarev idejni i etički stav, satira se ne zaustavlja samo na degradiranju, razobličavanju, demaskiranju i ogoljavanju, već osvjetljavajući stvarnu prirodu predmeta i pojava, angažirano im se suprotstavlja.

Iz naslova Za dobro naroda može se protumačiti osnovni smisao drame. Njena okosnica su fraze, prazne riječi, od kojih vlastodršci žive, one su zrak koji udišu, a legitimnost frazama daje nekritička svijest naroda, što potvrđuje manipulativnu intenciju fraze koja rezultira ideološkom sljepilu i povodljivosti puka. Sve što se radi, radi se $u$ ime naroda, što u političkoj, profanoj retorici predstavlja ekvivalent religijskog $u$ ime Boga. U Beloj hrizantemi - u kojoj Cankar odgovara na napade kritičarima - na jednom mjestu Cankar piše o pozitivnim idejama koje su istovjetne značenju fraza u drami Za dobro naroda. Imaginarna osoba $\mathrm{u}$ kojoj se Cankar ogleda prigovara mu kako ruši narodne ideale za koje Cankar smatra da iz njih kao iz kabla lije licemerje (Cankar 1968: 29).

$U$ ime naroda ili za dobro naroda i slovenska uzajamnost su vrhunaravne fraze. Nije teško primjetiti da u političkoj retorici postoje frekventni toposi (domovina, sveopšti interes, jedinstvo, tradicionalne vrijednosti, svetost, ideali) koji služe kao maska, kao strategija prikrivanja stvarnog stanja, kao generalizacija kojom se maskira pojedinačno i konkretno, na koncu, kojom se prikriva neangažiranost za stvarni sveopšti interes, i upravo je u tome jedan od najvećih problema fraze što ona potvrđuje ogroman jaz između ideje o nacionalnoj zajednici i interesu i fraze o njoj tj. laži o njoj. Besadržajnoj frazi buržoaskih vlastodržaca suprotstavlja se novinar Ščuka, predstavnik socio-demokratske inteligencije. Svojom replikom on iznosi način na koji funkcioniše politička retorika: Danas je laž tako poštovana [...] Istinu treba poštovati u teoriji, - za praksu ona nema nikakve vrednosti (Cankar 1946: 26). ${ }^{60}$

\footnotetext{
${ }^{60}$ Pišući o statusu istine i laži u političkoj sferi Arent (1994) navodi kako se istinoljublje nikada nije ubrajalo u političke vrline te da uspjeh u političkom životu ovisi o vještinama izvrtanja istine i retoričkim potencijalima oblikovanja stvarnosti. Pošto je lažov slobodan da oblikuje svoje 'ćinjenice' tako da budu podesne za postizanje dobiti ili zadovoljstva ili čak za puka očekivanja publike, on ima više izgleda da bude uverljiviji od onoga koji kazuje istinu (Arent 1994: 50). Kao savršen instrument ostvarivanja moći, najveći problem s laži je njen ogroman manipulativni potencijal, izvanredna mogućnost da sebe predstavi u ruhu istine, te uvjerljivost. Laži je potreban mehanizam uvjeravanja, a istina sama sebe potvrđuje.
} 
Vlastodršci u ovoj drami žive od fraza, a fraza je imenovanje nečega što ne postoji ili postoji ali samo imaginarno. Onaj ko u društvu imenuje stvari, taj i vlada, odnosno onaj ko kontorliše jezik i oficijelne narative, taj kontroliše i samo društvo. Ko frazu ismije i dovede $u$ pitanje taj biva ekskomuniciran, on je izdajica naroda, ideala, svetinja. Na prvi pogled fraze izgledaju bezopasne, samo prazne riječi, laž koja ne čini nasilje niti ubijaja, ali Ščuka, kao svjestan stvarnih društvenih problema, na jednom mjestu, povodom toga, replicira: Laž ne ubija batinom, ali uvlači se u vene kao otrov, polako i oprezno, ne primećuje se kako deluje (Cankar 1946: 38).

Jedan od suštinskih problema u ovoj drami krije se u tome što vlastodršci sebe poimaju kao narod. Grudenkova kaže: Narod smo mi [...] Ono što kažemo mi, kaže narod (Cankar 1946: 35). U tom smislu fraza $u$ ime naroda ima ironičan simao kao $u$ ime nas, što predstavlja vrhunac ironije. Najprisutniji satirični postupak ovdje je ironija putem koje se poroci i gluposti predstavljaju kao visoko vrijenosne vrline (laž, ucjena, sebičnost, licemjerje). Iza za dobro naroda ustvari krije se sebičnost vlastodržaca. Ščuka koji ruši ideale, podriva autoritete, raskrinkava moral i djelovanje vlastodržaca na kraju drame istupa sa svojom genijalnom replikom koja funkcioniše kao reflektor koji osvjetljava stvarno stanje:

Doktor Grozd bi želeo da bude ministar ili bar dvorski savetnik, - za dobro naroda. I doktor Gruden bi želeo da bude ministar ili dvorski savetnik, takođe za dobro naroda. Sve, dragi moji, za dobro naroda. Ko dandanas javno laže, - laže za dobro naroda. Ko govori javno istinu, - njega čine smešnim, progone ga i na kraju unište, - za dobro naroda [...] I za te vaše ideale [...] Grozd bi dao [...] svoju nećaku, a Gruden svoju ženu (Cankar 1946: 97).

Centralni lik drame Kralj Betajnove je Jožef Kantor, industrijalac koji svoju suprotstavljenu djelatnu energiju pronalazi u liku Maksa, mladića, običnog seljaka, ali moralnog, savjesnog lika i angažiranog s ciljem da uzdrma Kantorov oportunizam. Kantor je tipični šekspirovski lik koji u krvavoj igri prestolja ne bira sredstva. Princip njegovog političkog djelovanja sadržan je u sintagmi cilj opravdava sredstvo. Njegov stav je evolucionistički, naravno instrumentaliziran u smislu opravdavanja političkog djelovanja koje podrazumijeva opstanak najmoćnijih, najprilagodljivijih i najsnalažljivijih. Sintagma prirodna selekcija, koja je u pozadini Kantorovog djelovanja, čisti je 
eufemizam. ${ }^{61}$ Za Kantora prirodna selekcija postaje politički zakon neko prirodno otpada, a on ostaje jer se prilagodio surovom prirodnom zakonu u smislu odsustva savjesti kao vrhunaravne vrline i imperativa opstanka najmoćnijih. To je njegovo opravdanje za nehumane i nemoralne radnje. U većini replika, Kantor ima neko objašnjenje za zlodjela. Tu se ostvaruje satirični postupak nagomilavanja kojim se želi, putem stalnog ponavljanja, naglasiti i jasnije očitovati skrivena, unutarnja izopačenost, da se porok učini vidljivijim. Na jednom mjestu Kantor kaže: Grešio sam, jer sam morao grešiti (Cankar 1946: 224). Takvo opravdavanje je izrazito satirično jer se iznalazi poseban jezik koji vodi u iluzornost unutar koje se pod svaku cijenu opravdava i ono što se ne može opravdati. Pored toga, satira se naglašeno primjećuje i u ponašanju oragana vlasti, u ovom slučaju Sudije, koji istražuje ubistvo, gdje ga ne zanima ko je pravi ubica, već kako što lakše iznaći najracionalnije i najbezbolniji objašnjenje i za sebe i za druge. Iako mu Kantor neprestano ponavlja Ja sam ga ubio, Sudija to zanemaruje misleći da Kantor zbija šale s njim. Stvar je u tome da Kantor ne može biti ubica. Tu se potvrđuje njegova replika upućena Maksu: Ako bi sada moj kaput bio sav krvavi ako bi vi došli i pokazali: 'Gledajte, ubijao je, još je sav krvav!' - odmah bi Vas zgrabili za kose i otjerali u ludnicu. Kralj Betajnove ubica! Nije nego! Za šalu, iz dosade se malo poškropio krvlju! (Cankar 1946: 212, 213).

Kantor je ničeanski lik bez savjesti ili s ugušenom savješću kroz eufemizme i mehanizme opravdavanja zlodjela, putem kojih vješto priguši svaki pokušaj savjesti da progovori u njemu. On ne želi savjest jer ga savjest i moralna pitanja sputavaju da ide naprijed. Ali i takav nadčovjek biva podvrgnut satiri. On se plaši, boji se da ga ne otkriju kao ubicu, boji se da ne izgubi vlast i da ga porodica ne napusti. Time pokazuje da nije dovoljan sam sebi, da su mu potrebni drugi kako bi preko njih potvrđivao svoju svirepo stečenu nadmoć. U tom strahu da ne izgubi moć i vlast on je spreman poniziti se, ali i ubiti.

Strah je u drami Sablazan u dolini Šentflorijanskoj doveden do krajnosti i izrazite komičnosti. U njoj je vjerovatno najsnažnije denunciran malograđanski moral. Glavni lik Krištof dolazi u dolinu predstavljajući se kao izgubljeni vanbračni dječak Petar čime ucjenjuje žitelje doline, a za šutnju uzima razna bogatstva koja mu Šentflorijanci

\footnotetext{
${ }^{61}$ Eufemizmi su retoričke figure koje su zbog svoje manipulativne funkcije od izrazite važnosti ne samo u političkom diskursu, već i u svakodnevici. Oni služe da lakše izađemo na kraj sa stravičnom realnošću, da opravdamo nehumane postupke, distancirmo od stvarnosti ublaženicama kojima projiciramo neku novu, utješniju stvarnost.
} 
daju iz straha da ne otkrije ko su roditelji. To je sjajan komični i satirični postupak kojim se naglašava da su vanbračni odnosi izrazito ustaljeni što svjedoči moralni sunovrat malograđanštine. Motiv ugovora s đavolom, ali izvrnut, farsičan, po kojem Đavo traži od Krištofa da mu proda duše stanovnika doline, neslavno završava za Đavola. Duše Šentflorijanaca su dotle nemoralne da od njih nije ostalo ništa što bi Đavo mogao pokvariti. Oni su nadđavolili samog đavola i takav obrat je sjajan farsični element, ali i satirični s obzirom da tadašnju malograđanštinu kritizira i predstavlja većim đavolima od samog đavola.

Najsnažniji napad na povodljivost i sljepilo naroda Cankar je izvršio u drami Sluge, gdje narod sam bira svoj položaj roba pod klerofašističkim gospodarima koje utjelovljuje Župnik koji iznevjerava izvorna načela hrišćanstva i okreće se svjetovnim vrijednostima, motiviran voljom za moć. U liku Župnika satira svoj izraz nalazi u njegovom skrivanju iza ideala hrišćanstva zarad postizanja vlastitog interesa u vidu sticanja apsolutne vlasti. Želeći da pridobije Jermana, Župnik mu govori: nikome [...] ne gledam na usta da li se prekrstio pre no što je zagrizao; ne pitam ga za grehe, ne teram ga u crkvu. Ali jedno je potrebno i to je kao zapovest: da pokaže na mene kad ga pitaju ko mu je gospodar (Cankar 1946: 142). Župnikove pretenzije na apsolutnu vlast prozire Jerman koji svojim djelovanjem ogoljava instrumentalizaciju vjere. Kontrast njegovom djelovanju protiv klerofašizma je narod što u takvom opozicionom odnosu uvećava satirično predstavljanje puka kao povodljivog i kontroliranog mehanizmima straha od kazne. Gospodar se menja, a bič ostaje, i ostaće večito, zato što su leđa povijena, na bič navikla i biča željna (Cankar 1946: 157).

U svim dramama koje su predmet analize, prisutan je lik koji otkriva potkožne slojeve, ogoljava privid čime dovodi u pitanje postojeće stanje. U dramski odnos stupaju s jedne strane, nemoralni i nesavjesni likovi (Grozd, Gruden, Župnik, Kantor) koje isključivo motivira sebični interes, a s druge strane, moralni i savjesni likovi (Ščuka, Jerman, Maks) motivirani humanim i univerzalnim načelima, likovi koji prepoznaju društvene anomalije i suprotstavljaju im se. Takvi likovi uzdrmavaju status quo, te ga nastoje promjeniti.

Cankar je isticao da mu se gadi i da mu je odvratna ona umetnost koja ne može da kaže čoveku ništa, koja je bez 'svrhe' (Ziherl 1956: 25). Umjetnost mora biti angažirana, mijenjati, prepoznavati društvene anomalije, otkrivati ono što narod ne primjeti i rasvjetljavati najskrivenije uglove društvene zbilje. U drami Sablazan u dolini Šentflorijanskoj 
satirički je prikazan umjetnik malograđanin koji je varalica, razbojnik, razvratnik, koji je pokleknuo pred izazovima buržoaskog života. To je (pseudo)umjetnik koji gubi vlastiti identitet (Petar/ Krištof, umjetnik/ razbojnik), koji, poput Siratke u Za dobro naroda, nije slobodouman i angažiran već rob i afirmator postojećeg trulog poretka koji zajedno sa vlastodršcima drži narod u iluziji. U Beloj hrizantemi Cankar piše: Kazujem mu (narodu) kakoje malen, kakoje malodušan, kako tumara bez volje i bez cilja; pokazujem mu diku beznačelnosti, čašćenja licemerja, slavu laži; zato da se probudi, da shvati ko je i gde je, te da pogleda u budućnost (Cankar 1968: 67). Zbog toga Cankar koristi satiru jer u njoj vidi edukativni i etički učinak. Cankar svojom umjetnošću nastoji mobilizirati masu protiv reakcije i iskorišćavanja, shvatajuću umjetnost kao aktivnu snagu u procesu preobražavanja društvenih prilika.

\section{Izvori}

Ivan CANKAR, 1977: Drame. Novi Sad: Matica srpska

Ivan CANKAR, 1946: Tri drame. Beograd: Državni izdavački zavod Jugoslavije

\section{Literatura}

Hana ARENT, 1994: Istina i laž u politici. Beograd: Filip Višnjić

Boris ZIHERL, 1956: „Ivan Cankar i njegovo doba“. U: Cankar, Ivan. Eseji kritike i feljtoni. Pr. Milica Carcaračević. Beograd: Prosveta, 9-39.

Ivan CANKAR, 1968: Bela krizantema - Bela hrizantema. Ljubljana: Državna založba Slovenije; Beograd: Prosveta

Darko LUKIĆ, 2018: „Pitanja o mogućnostima satire u tranzicijskim društvima“. U: Satire und Komik in der bosnisch-herzegowinischen, kroatischen, montenegrinischen und serbischen Literatur. Ur. Renate HansenKokoruš / Darko Lukić / Boris Senker. Hamburg: Verlag Dr. Kovač, 2018. (Grazer Studien zur Slawistik, 10). 251-268.

Norhtop FRYE, 2000: Anatomija kritike: četiri eseja. Zagreb: Golden marketing.

Andre JOLLES, 2000: Jednostavni oblici. Zagreb: Matica hrvatska

Žan-Pol SARTR, 1981: Šta je književnost. Beograd: Nolit

Zdenko LEŠIĆ, 1986: „Satira“. U: Rečnik književnih termina. Gl. ur. Dragiša Živković. Beograd: Nolit, 694-697. 


\title{
Ahmed Isanović
}

\section{SATIRICAL APROACH TO MORAL AND SOCIOPOLITICAL PROBLEMS IN THE PLAYS OF IVAN CANKAR}

\begin{abstract}
Summary:
Analyzing the satirical devices in the dramas Za narodov blagor, Hlapci, Kralj na Betajnovi and Pohujšanje v dolini šentflorijanski, I try to emphasize the engaged character of Cankar's scenic creativity which finds its primary technique in satire as a perfect ethical and subversive devices by which Cankar attacks and breaks down the negative sides of its current reality, thus expressing the aspiration to change the sociopolitical context.
\end{abstract}

Keywords: satire, drama, engaged literature, socio-political moral 